\title{
Articles
}

\section{Best Practices of Small Business Development Centers with Host Institutions}

\author{
Jennifer A. Irvin', Jana R. Minifie², Damilola Runsewe ${ }^{3}$, William G. Thompson ${ }^{4}$ \\ ${ }^{1}$ Department of Chemistry and Biochemistry, Texas State University, ${ }^{2}$ Department of Management, Texas State University, ${ }^{3}$ Materials Science, \\ Engineering and Commercialization Program, Texas State University, 4 Texas State University Small Business Development Center, Texas State \\ University \\ Keywords: small business development center, best practices, entrepreneurship, student consulting \\ https://doi.org/10.53703/001c.28167
}

\section{Small Business Institute Journal}

Vol. 17, Issue 1, 2021

In 1980, the law creating Small Business Development Centers (SBDCs) was enacted. As part of the law, funding for local SBDCs comes from both the Small Business Administration (SBA) and a host institution such as a university and/or community college. The relationship between the host institution and the SBDC is not well defined except through the financial commitment. This research was an exploratory investigation to determine the extent in which SBDCs interact, if any, with their host institution. An open-ended survey was designed and distributed to over 600 SBDC Advisors as listed in America's Small Business Development Centers' (ASBDC) contact list. A total of 57 surveys were completed by the respondents. This research presents the summary of these questions as to the type of interaction, which students, and what activities these advisors had with the students of their host institution.

\section{INTRODUCTION}

Per America's Small Business Develop Center (ASBDC) (America's SBDC Organization, About Us, 2018), the exact genesis of the Small Business Develop Center (SBDC) is difficult to pinpoint as the concept has evolved over the years. In the 1940s, university-based business extension was introduced by Congress. This was followed by legislation in 1953, forming the Small Business Administration (SBA). This action recognized the importance of small businesses to the nation's economy and that support by our federal government was needed for the success of small businesses.

In 1975, William C. Flewellen, Jr., Dean of the College of Business Administration at the University of Georgia and Reed Powell, of the California State Polytechnic University at Pomona, approached the SBA stating that “...the nation as a whole - would benefit from a small business program that offered the resources of higher education, small business and government." (America's SBDC Organization, About Us, 2018) From this, the University Business Development Center (UBDC) program was announced during the 1976 Small Business Week activities. Due to the benefits of the UBDC program, the SBDC went into law in 1980. SBDC centers were formed to have a partnership with the SBA, state governments, and a host college or university institution. There are 64 lead SBDC service centers in the United States, the District of Columbia, Puerto Rico, the US Virgin Islands, and American Samoa. SBDC centers aid entrepreneurs and small businesses in areas of marketing and business strategy, finance, engineering, management, and other areas (Congressional Research Service, 2017).

By design, SBDC centers offers support in areas that are commonly taught subjects by the host college or university.
These areas of support range from initial startup to growth strategies for small businesses. SBDCs offer services that bring together resources from higher education, small business, and government.

This underlying impetus of SBDCs generated discussion as to the extent that SBDCs were using resources from higher education, and if so, how they were using these resources. A review of the literature revealed an indirect use of higher education resources (courses) in the form of experiential learning (Cook et al., 2013, 2016; Geho \& McDowell, 2015; Kosnik et al., 2013), with specific course work (Minifie, 2018), and with specific type of clients. While the benefits of bringing SBDCs into the classroom have been delineated (Knotts, 2011; McDowell \& Geho, 2015), previous research has not addressed best practices of host institutions and their SBDC centers. This led us to conduct informal interviews with select SBDC Directors. It was determined that there was no consistent or suggested set of best practices of SBDC centers with their host institutions. In fact, from this very small sample of personal interviews with SBDC directors, it was determined that the interaction of SBDC centers with their host institutions varied greatly.

This research is an initial investigation to determine how SBDCs incorporate their host institution in supporting their small business clients. The goal of the research is to investigate interactions of SBDCs with their host institutions and develop a list of best practices that could be shared among the various SBDCs. Identifying best practices is expected to enhance the relationship between the SBDC and the host institution and to increase metrics in entrepreneurial growth, both from the university and the community served by the SBDC. For the SBDC, an understanding of best practices could increase their ability to service clients 
more effectively, thereby improving the SBDC's performance metrics and potentially increasing the potential for additional funding for the SBDC. For universities, understanding best practices could increase experiential learning opportunities for students, enabling students to positively impact their communities, which is important for colleges of business that maintain AACSB International Accreditation (AACSB, 2021).

Some of the research questions include:

- Are experiential courses using SBDC small business clients as community partners?

- How involved, if any, are SBDCs with their host institution in terms of assisting their small business clients?

- Do SBDCs use the expertise of the host institution's faculty for developing their training materials and teaching of their workshops?

- Do SBDCs have a preference for undergraduate and/or graduate students from their host institution?

- Does the SBDC only interact within the partnered College/Department of the host institution?

- What type of support do they provide for the host institution and what type of resources from the host institution do they utilize in aiding small businesses?

- If they don't currently work with their host institution, would they want to have this relationship in order to better serve their clients?

- In recent years, the funding of SBDC centers has not kept up with inflation, and in some cases financial support of SBDC centers has decreased. In order to maintain the same level of commitment to their clients, have SBDC centers utilized the student resources of their host institution?

\section{METHODOLOGY}

To determine what the best practices were of SBDC centers with their host institutions, a survey was developed. The survey included mostly open-ended questions since there wasn't supporting previous research to use as a basis for the survey. For this first round of surveys, the intention was exploratory in nature, to determine what are some of the relationships between the SBDC and host institution so that a more finite, shorter survey could be developed to determine consensus of practices with SBDCs. The survey questions were grouped into three areas: SBDC respondents that worked with students from their host institution, respondents who didn't currently with students from their host institution, and general questions for all respondents.

Work with Students:

- Do you work with students from your host institution?

- College Interaction: Which colleges do you work with at your host institution?

- Type of Student: Do you work with undergraduate, graduate or both students from your host institution?

- Preference for Type: Why do you prefer to work with undergraduate or graduate students?

- Benefits: What are the benefits of working with students from your host institution?

- Improvements Required: What would improve your abil- ity to work with host institution students?

- Length of Time: How long have you been working with students from your host institution?

- SBDC with Host: Explain how you work with your host institution?

\section{Doesn't work with students:}

- Would you like to work with graduate or undergraduate students at your host university?

- In what capacity would you like to work with students?

- What do you think keeps you from working with the host institution's students?

\section{All Respondents:}

- What would improve your ability to work with students from your host institution?

- Is there anything else that you think we should know about the SBDC working with their host institution?

The survey was posted to Typform.com so that participants could be moved between questions, depending on their answers to specific questions. The survey was designed to determine what best practices that SBDC's have with their host institution.

The survey was distributed via email to SBDC Advisors from the America's Small Business Development Center (ASBDC) website list of members (America's SBDC Organization, Find Your Advisor, 2018). ASBDC represents the nationwide network of SBDCs in the United States and its territories. There are approximately 900 local centers available to assist small businesses with no-cost business consulting and low-cost training to new and existing businesses. Each of the individual offices are associated with one of the ten district offices and seventy regional offices.

Free responses to survey questions were analyzed via an inductive coding approach utilizing a constant comparative method (Saldaña, 2015). No prior research was available to group common sets of responses, but responses generally fell into logical sets. The authors each coded the responses, discussed areas of disagreement, and reached consensus, adjusting code definitions as needed.

\section{SURVEY RESULTS}

IRB approval was obtained, and the link to the survey was emailed to contacts on the ASBDC. A total of 623 emails were sent to contacts on the ASBDC. An initial email was sent, then a follow up email was sent a month later to those who hadn't entered their email address on question 1 of the survey. Seventy-four (12\%) of the initial emails were returned as an invalid/no longer active email address, while 8 (1\%) were returned with an updated email address. This resulted in a sample of 549 ( $88 \%$ of the original list) emails being sent, and assumed received, by the SBDC advisor listed in the ASBDC list. A total of 57 (10\%) surveys were completed, which represented 55 different universities. Table 1 shows the key statistics of visits to the Typeform website.

Of the 549 emails that were sent to SBDC advisors, 166 (30\%) survey respondents (unique visits) opened the survey to view it. Even with repeat visits to the site (an additional 60 visits from the 166 unique visits), only 57 (10\%) com- 
Table 1. Key Statistics of Survey Website

\begin{tabular}{|c|c|c|c|c|c|}
\hline Device & Responses & $\begin{array}{l}\text { Total } \\
\text { Visits }\end{array}$ & $\begin{array}{l}\text { Unique } \\
\text { Visits }\end{array}$ & $\begin{array}{l}\text { Completion } \\
\text { Rate }\end{array}$ & $\begin{array}{c}\text { Average Time to Complete } \\
\text { (Minutes) }\end{array}$ \\
\hline $\begin{array}{l}\text { PC \& } \\
\text { Laptops }\end{array}$ & 54 & 208 & 150 & $36 \%$ & $12: 00$ \\
\hline $\begin{array}{l}\text { Smart } \\
\text { Phones }\end{array}$ & 3 & 15 & 13 & $23 \%$ & 8:16 \\
\hline Tablets & 0 & 3 & 3 & $0 \%$ & 0:00 \\
\hline All Devices & 57 & 226 & 166 & $34 \%$ & $11: 48$ \\
\hline
\end{tabular}

Table 2. Student Major at Host Institution

\begin{tabular}{|c|c|c|}
\hline Major & \% Response & \# of Responses \\
\hline Business & $93 \%$ & 38 \\
\hline Computer Information Systems & $49 \%$ & 20 \\
\hline Science (Biology, Chemistry, Physics, etc.) & $22 \%$ & 9 \\
\hline Agriculture & $12 \%$ & 9 \\
\hline Arts & $12 \%$ & 5 \\
\hline Food \& Nutrition & $12 \%$ & 5 \\
\hline Fashion Design & $7 \%$ & 3 \\
\hline Other: Please List & $22 \%$ & 9 \\
\hline Internships & & 1 \\
\hline Engineering & & 2 \\
\hline Communication & & 2 \\
\hline Whatever else we have & & 1 \\
\hline Engineering \& Engineering Technology & & 1 \\
\hline Engineering, Communications, Fine Arts & & 1 \\
\hline Applied Accounting, Mechanics, Industrial Technology & & 1 \\
\hline
\end{tabular}

pleted the survey. This represents a $34 \%$ completion rate of those visiting the survey website. It is assumed that the time required to complete the survey could have been the main determinant, because the majority of the questions were open-ended. The average time to complete the survey was over 8 minutes on Smart Phones with 12 minutes on PCs \& Laptops.

\section{WORKING WITH STUDENTS}

For the question, 'Do you work with students from your host institution?' 56 responded to the question, with 41 saying yes (73\%), and 15 saying no (27\%). Of those that did work with students $(n=41), 98 \%$ worked with undergraduate students, $61 \%$ worked with graduate students, and $2 \%$ worked with Ph.D. students. $42 \%$ of respondents reported working with both undergraduate and graduate students. (Please see Table 4 discussion regarding what it would take to work with host institution students below.)

Of the 15 respondents that did not currently work with students from their host institution, they were asked if they would like to work with students. The majority of the respondents indicated that they were open to the possibility of working with students: 8 (53\%) selected "Maybe" and 6 (40\%) selected "Yes", while just 1 (7\%) respondent selected "No".

\section{STUDENT MAJORS}

The majors of the students that SBDC advisors indicated that they worked with varied, with the majority of students in the business field (93\%). See Table 2.

\section{STUDENT DEGREE LEVEL}

When asked if they worked with graduate and/or undergraduate students, 25 (61\%) indicated that they worked with both undergraduate and graduate students, whereas 12 (29\%) worked with only undergraduate students, and 4 (10\%) worked with only graduate students (Table 3). The major reason that many of the respondents indicated as their preference for working with undergraduates (43\%) was that their host institution only had undergraduate programs; there weren't graduate programs offered at their host institution (Table 4). 
Table 3. Level of Students

\begin{tabular}{lcc}
\hline \multicolumn{1}{c}{ Student Level } & \% Responses \\
\hline & & $29 \%$ \\
Only undergraduate students & 12 \\
Undergraduate and graduate students & $61 \%$ \\
Only graduate students & $10 \%$ \\
\hline
\end{tabular}

Table 4. Reason for Preference of Undergraduate/Graduate Students

\begin{tabular}{|c|c|c|}
\hline Preference Reason & $\begin{array}{c}\% \\
\text { Responses }\end{array}$ & $\begin{array}{c}\# \\
\text { Responses }\end{array}$ \\
\hline Only undergraduates at institution & $43 \%$ & 7 \\
\hline $\begin{array}{l}\text { Graduate students typically are more focused on specific subjects, have gained a greater level of } \\
\text { maturity and discipline }\end{array}$ & $12 \%$ & 2 \\
\hline Accessibility & $6 \%$ & 1 \\
\hline Either & $6 \%$ & 1 \\
\hline $\begin{array}{l}\text { Hire undergraduates to work in the Lead Center and in the Research Center. We also work with } \\
\text { professors to have students' complete projects or research for clients }\end{array}$ & $6 \%$ & 1 \\
\hline Most often we offer support to the Entrepreneurship class as well as offer internships & $6 \%$ & 1 \\
\hline They (graduate students) are hungry for information and are open to learn & $6 \%$ & 1 \\
\hline We have them as interns & $6 \%$ & 1 \\
\hline
\end{tabular}

Table 5. Benefits of Working with Host Institution Students

\begin{tabular}{l|c|c}
\multicolumn{1}{c|}{ Benefit } & \% Responses & \# Responses \\
\hline Students & $53 \%$ & 21 \\
Host Institution & $30 \%$ & 12 \\
Clients & $28 \%$ & 11 \\
SBDC & $48 \%$ & 19 \\
Other & $5 \%$ & 3 \\
\hline
\end{tabular}

\section{BENEFITS OF WORKING WITH HOST INSTITUTION STUDENTS}

When asked about the benefits of working with the Host institution students, respondents' comments could be categorized into 5 different categories: students, host insitution, clients, SBDC, and other. See Table 5.

Students: The most common response regarding the interaction of the SBDC interatction with the host institution students, was that the students got to "work on real world applications." From working with the SBDC, students gained "hands-on experience," "tremendous service/experiential learning," and "practical insight and experience with the discliplines that they are studying." From this experience, students "develop a career path, refine their skills, and earn a little bit of cash." One repsondant stated that the experience helped students to "gain confidence and transition to a job," while another mentioned "increased job opportunities." The students that worked with the SBDC, became "ambassadors" by referring clients, becoming clients themselves, or recruiting other students.

Host Institution: Respondents stated the host "institution is appreciative" of the interaction with their students by providing faculty and students with "real business activity and trends that are more valuable than case studies." The interaction "helps spark the entrepreneurship conversation on campus." Additionally, the "university develops more competitive and valuable graduates, and the credibility of the program opens more doors for additional alumni donations." Another respondent summarized the benefit to the university by saying "University Administrators (particularly the Deans) love that we deliver real life learning opportunities to work with businesses."

Clients: Statements regarding students working with SBDC clients revolved around the statement of "the business benefits by developing a potential pipeline of new recruits; by evaluating the interns in risk free environment, new innovative ideas are brought to the business in problem solving situations." The clients benefited from the students and SBDC advisors by the "intergenerational ideas". Clients were appreciative of the "new ideas, methods, and research for the 
Table 6. What Change Would be Needed to Work with More Students?

\begin{tabular}{|c|c|c|}
\hline Reason & $\begin{array}{c}\% \\
\text { Responses }\end{array}$ & $\begin{array}{c}\# \\
\text { Responses }\end{array}$ \\
\hline No change ... our door is open to all. & $31 \%$ & 5 \\
\hline More funding for internships \& for staff to supervise additional students & $12 \%$ & 2 \\
\hline Someone from the department to ask us to, we'd find a way to make that work & $12 \%$ & 2 \\
\hline We don't have a graduate program & $12 \%$ & 2 \\
\hline Better access to students, distance, time and financial resources & $6 \%$ & 1 \\
\hline Champion from Dean + Professor + SBDC consultant $=$ Success & $6 \%$ & 1 \\
\hline Greater exposure of our service & $6 \%$ & 1 \\
\hline Money & $6 \%$ & 1 \\
\hline $\begin{array}{l}\text { While we enjoy students, it is time consuming and is not included in our performance } \\
\text { measures. }\end{array}$ & $6 \%$ & 1 \\
\hline
\end{tabular}

Table 7. Interaction with Host Institution

\begin{tabular}{lcc}
\hline \multicolumn{1}{c}{ Reason } & \% Responses & \# Responses \\
\hline Assist within the SBDC offices & $90 \%$ \\
Work directly with host institution classes & $49 \%$ \\
Work with students as clients & $37 \%$ & 37 \\
Work directly with host institution events & $32 \%$ \\
Arrange to work with SBDC clients & $7 \%$ \\
Work with host institution organizations & $3 \%$ \\
\hline
\end{tabular}

clients." The clients "appreciated the process and the outcomes."

SBDC: Having students work with clients, the SBDC can "leverage" budgets and in turn is able to assist more clients. The relations between the SBDC and the host institution are able to "build stronger bonds with the campus and the academic mission.” The SBDC enjoyed working with students, as one respondent stated that represented other responses with "Renews our spirit to have young minds providing input!"

\section{LENGTH OF TIME}

The length of time that advisors worked with students at their host institution varied from not reporting the actual time ("unsure", "since inception") to stating the actual number of years (6-months to 40 years). The average of those reporting the length of their interaction was 14 years.

\section{IMPROVEMENTS REQUIRED}

Advisors who don't work with students were asked what it would take for the advisors to start working with students. These reasons are listed in Table 6. Two major categories that would improve the working relationship between the SBDC and the host university were identified by participants. From the Host university side, there needs to be a champion to encourage students to work with the SBDC. Host universities need to establish a shared sense of com- munity between the university and the SBDC. Universities need to ensure that faculty and students are aware of the services of the SBDC. Upper Administration at the Host university needs to be a champion for the SBDC.

Working with the Host university needs to be a priority for SBDC offices. SBDC offices receive metrics and funding from both the University and the SBA. Both of these funding sources need to identify the importance of the SBDC advisors in working with the Host institution faculty and students in terms of the metrics and the resources to support those metrics.

\section{SBDC WITH HOST}

When asked what work the SBDC advisor does with their host institution, the 41 open-ended responses varied greatly. The open-ended responses fell into 6 distinct categories: assist within the ASBDC offices, work directly with host institution classes, work with students as clients, work directly with host institution events, arrange to work with SBDC clients, and work with host institution organizations. See Table 7.

Assist Within the SBDC Offices: Of the SBDC advisors responding that they interacted with the students of their host institutions, 37 responses (90\%) indicated that they supported their SBDC activities with the assistance of host institution students. Both graduate and undergraduate students were noted as assistants. The majority of the respondents indicated that they had student "interns" (10 of 37) to 
Table 8. Student Intern Tasks Within SBDC Offices

\begin{tabular}{|l|l|}
\hline Business Tasks & Administrative Tasks \\
\hline research & clerical tasks \\
\hline data collection & website development and maintenance \\
\hline data analysis & \\
\hline preparation of client employee handbooks and marketing plans & \\
\hline maintaining a social media presence & \\
\hline preparing press releases and marketing flyers & \\
\hline working on client projects and business plan development & \\
\hline
\end{tabular}

assist advisors in a variety of business areas, and students also assisted in "administrative” work (Table 8). While not specifically asked, three of the responses specifically stated that the interns were paid. One response stated that students were trained to perform duties that would otherwise be performed by full time staff.

Work Directly with Host Institution Classes: The next most popular response was that SBDC advisors work directly with their host institution's classes. The most common response ( 5 out of 20 ) was that advisors assisted business plan class teams to prepare for competitions. The next most common response (4 out of 20) was providing (identifying) SBDC clients for class room projects (marketing, undergraduate digital marketing, and human resources classes) and actual classroom lectures (4 out of 20) by being guest lecturers, providing classroom instruction in entrepreneurship classes. Two of the responses indicated that advisors worked with senior/capstone projects by providing guidance, information, and feedback on the project, plans, and/or proposals. One host institution offers an MBA that requires a Practicum, where students work with a small business project; the SBDC assists in identifying those clients. In other cases, the SBDC provides IBIS World Reports for class projects. Students, sometimes an entire class with faculty supervision, work on specific business challenges or on the SBDC's research needs. Lastly, one response said that the SBDC advisors provided guidance on graduate student research.

Work with Students as Clients: The majority of the responses in this category (6 out of 15), simply stated that SBDC advisors work with students as clients. Another response in this category (2 out of 15 ) stated that advisors counsel and/or coach students. They did not specifically state if this was through classes. Other responses in this category included: advisors continue to work with students as alumni, they work with students who want to start their businesses, they talk with students at the Entrepreneur Center, they provide consulting services for undergraduate and graduate entrepreneurial students, and that the SBDC offered business consulting to students interested in starting their own business.

Work Directly with Host Institution Events: The most common response (3 out of 13) was that SBDC advisors worked with their universities to hold "pitch competitions". Other responses were more specific in how they interact with the host institution's events. One responded that they co-host an all-day Entrepreneur Summit with guest entrepreneur speakers with their host institution. Another said that they assist by coaching for two pitch competitions at their host institution. Another works with undergraduate entrepreneurial students to host "Lemonade Day"; a national program that teaches youth about entrepreneurship. SBDC advisors assist with venture coaching, panel discussions, and business plan competitions with their host institution. They also serve as judges/critiques for various projects, as well as work with student events such as pitch events and hackathons. SBDC Advisors coach annual pitch competitions at their host institution. The SBDC invites student to attend their trainings and workshops.

Arrange to Work with SBDC Clients: Three of the responses indicated that advisors serve as a conduit between the host institution's students and SBDC client businesses. Two of the SBDC advisors indicated that students received paid internships with local businesses. One of these was paid from SBDC grant funds.

Work with Host Institution Organizations: SBDC advisors serve as student club advisors (2 out of 3 ). Another respondent indicated that they operate a Women's Entrepreneurship Center in partnership with their host institution.

\section{DISCUSSION}

The range of activities that SBDC advisors pursues with their host institutions varies greatly between the 57 respondents, with $28 \%$ of the respondents indicating that they don't interact with their host institution. Among those that did have interaction with the students from their host institution, the activities varied from simply incorporating students into the normal duties of the SBDC to providing support for their host institution's classes and events. Sharing these findings with all SBDCs will provide SBDC advisors with inspiration for enhancing their interactions with their host institutions, to the benefit of students, clients, and SBDCs alike.

Champions at the host institutions are needed to effectively engage the SBDCs, and educating the host institutions about the potential benefits to the institutions and their students is a likely way to find those champions. It is clear that when students work with SBDCs, the practical experience the students gain working with small business clients helps the students to refine their skills, earn money, 
and boost their resumes. There may be an additional benefit to non-traditional students, who are known to seek nontraditional modes of learning such as those provided by experiential learning opportunities (Cantor, 1995). Clients benefit from the students' innovative ideas and can evaluate the students for future employment. Host institutions benefit from having the SBDC interact with their classes and student clubs. The host institutions are also able to provide their students with real-world business problems rather than case studies, which leads to stronger graduates and potential alumni donations. Finally, SBDCs that work with students benefit by being able to use students to leverage their budgets, allowing the SBDCs to assist more clients and build stronger ties with their host institutions.

This initial research effort indicates a need to expand the research with a follow-on survey. Now that we are aware of the different types of activities that SBDC Advisors participate in with their host institution, a new survey can be developed to be more specific regarding the information that wasn't provided through the open-ended questions.

Additional areas to be considered in future research, as suggested by respondents, could be groups into three different categories: SBDC Operational Issues, SBDC Metrics, and Host Institution Evaluation.

\section{SBDC Operational Issues:}

- Do host organizations qualify the students to work with SBDC's, specifically confidentiality issues?

- When asking about students, include alumni as well.

- What would it take to include graduate students (especially MBAs) as counselors?

- How do advisors manage the supervision of students working with clients?

- How to use students to recruit new students to work with the SBDC?

\section{SBDC Metrics:}

- How are metrics being captured by the SBDC for student activity: Are students actively launching "real world" businesses with support from the host institution? How do SBDCs measure, track, and improve on student engagement? How to balance being a good partner with the host institution while meeting SBDC requirements? What type of evaluation measures are used for student, faculty, and community impact? How many students each year are involved in SBDC programs?

- Ask for and share suggestions as to how to engage students to improve scorecard performance.

- How did the students use their experiences after graduation: did they start a business or get a job? How did it impact their ability to get a job or start a business?

- Record keeping and reporting are both important to effectively measure success AND failure. There is a need to establish best practices, tools for measurement, and tips to expand this valuable interaction between the SBDCs and their host institutions.

\section{Host Institution Evaluation:}

- Host institution perceptions: Does the host institu- tion clearly understand the role of the SBDC? Does the host institution understand the value provided to the small business community by the SBDC? What is the size of the host institution? What does the SBDC require from the host institution? What does the host institution require from the SBDC? What challenges does the SBDC have in trying to meet the requirements from the host institution? What level of the host institution does the SBDC report to? Does this make a difference in the inclusion of students from the host institution?

- Does the university contribute financially? Is the SBDC located on or off campus?

Our initial investigation was from the perspective of the "best practices" of SBDCs with their host institution. It is clear from the suggestions for future research that best practices extend beyond the actual activities. The underlying relationship between the SBDC and the host institution also needs to be examined to determine what underlying relationships (conditions) are required for a successful relationship between SBDCs and their host institutions. Obviously, there are more research questions that need to be investigated in this area.

\section{CONCLUSIONS}

SBDCs indirectly make use of higher education resources to incorporate experiential learning benefits to host university members. However, there is no list of best practices that is currently available to improve the interactions between host institutions and SBDCs. The findings reported herein show that $72 \%$ of SBDC respondents reported that they had some level of active interaction with the host institution. A substantial majority (73\%) of SBDC respondents work with students, with an emphasis on undergraduate students and business students. The respondents reported that the SBDC interaction with the host institution provided benefits such as experiential learning opportunities for the students, more competitive graduates, creation of a potential pipeline of new employees for the clients, and leverage of the SBDC's budget to assist more clients. These preliminary results provide a window of opportunity to explore more than just the current activities but also areas where improvements can be made such as the SBDC operational issues, host institution evaluation, and SBDC metrics.

\section{ACKNOWLEDGEMENTS}

The authors would like to thank the National Science Foundation (grant \# 1829144) for funding.

Submitted: July 10, 2020 MST, Accepted: September 11, 2021 MST 
This is an open-access article distributed under the terms of the Creative Commons Attribution 4.0 International License (CCBY-4.0). View this license's legal deed at http://creativecommons.org/licenses/by/4.0 and legal code at http://creativecommons.org/licenses/by/4.0/legalcode for more information. 


\section{REFERENCES}

AACSB. (2021). Connected for Better. https://www.aacs b.edu/about/advocacy-and-awareness/societal-impac $\underline{\mathrm{t}}$

America's SBDC Organization, About Us. (2018). October. https://americassbdc.org/about-us/a-brief-history/

America's SBDC Organization, Find Your Advisor. (2018, June 11). https://americassbdc.org/small-business-co nsulting-and-training/find-your-sbdc/

Cantor, J. (1995). Experiential learning in higher education: Linking classroom and community (ASHEERIC Higher Education Report No. 7). ERIC Clearinghouse on Higher Education.

Congressional Research Service. (2017, March 16). Small Business Administration (SBA) Funding: Overview and Recent Trends. https://www.everycrsreport.com/files/2 0170316_R43846_926d413c939fd7fd2ea0d94c4ea2dde 95278c8dd.pdf

Cook, R. G., Belliveau, P., \& Campbell, D. (2016). The Experiential Student Team Consulting Process: A Problem-Based Model for Consulting and ServiceLearning (4th ed.). Cengage Learning.

Cook, R. G., Campbell, D. K., \& Kopp, A. (2013). Student Focused Community Engagement: The SBI Program as a Bridge into the Community, Small Business Institute ${ }^{\circledR}$ Journal, (Oct) 1-10. Small Business Institute ${ }^{\circledR}$ Journal. https://www.sbij.org/index.php/SBIJ/index

Geho, P. R., \& McDowell, W. C. (2015). The Small Business Institute and Small Business Development Center Network Collaboration. Student Experiential Learning Opportunities, Small Business InstituteÒ Journal, 11(1), 1-5. https://www.sbij.org/index.php/S BIJ/index
Knotts, T. L. (2011). The SBDC in the Classroom: Providing Experiential Learning Opportunities at Different Entrepreneurial Stages. Journal of Entrepreneurship Education, 14, 25-38. https://searc h.proquest.com/openview/e9f5f65148b683108ff65b42 6edbd1f9/1?pq-origsite $=$ gscholar \&cbl=28224

Kosnik, R. D., Tingle, J. K., \& Blanton, III, E. L. (2013). Transformational learning in business education: The pivotal role of experiential learning projects. American Journal of Business Education (AJBE), 6(6), 613-630. https://doi.org/10.19030/ajbe.v6i6.8166

McDowell, W. C., \& Geho, P. (2015). The Small Business Institute and Small Business Development Center Network Collaboration: Student Experiential Learning Opportunities. Small Business Institute Journal, 11(1), 1-5. https://www.researchgate.net/pub lication/277664477 The Small_Business Institute_an d_Small_Business_Development_Center_network_coll aboration_Student_experiential_learning_opportuniti es

Minifie, J. R. (2018). Best Practice: Experiential Business Classes and SBDC Clients, Presented at the Small Business Institute ${ }^{\circledR}$ Conference, Corpus Christi, TX, Feb., 2018. http://www.smallbusinessinstitute.biz/res ources/Documents/Final\%20Proceedings.pdf

Saldaña, J. M. (2015). The coding manual for qualitative researchers (3rd ed.). SAGE Publications.Texas SBDC Impact. https://txsbdc.org/our-impact/ 